\title{
sciendo
}

\section{The Impact of Rule Modifications on Elite Basketball Teams' Performance}

\author{
by \\ Sergio J. Ibañez ${ }^{1,4}$, Javier García-Rubio,4, Miguel-Ángel Gómez \\ Sergio Gonzalez-Espinosa ${ }^{1,4}$
}

\begin{abstract}
Rule modifications in basketball are used to develop the sport, and FIBA changes the basketball regulations periodically and constantly in search of a more attractive game. The objectives of this study were as follows: i) to characterise and identify the technical-tactical performance indicators which discriminated the game style according to the effect of rule modifications; and ii) to analyse the persistence of these indicators according to rule modifications over time. Analyses were made of all the editions of the current competition system of the Copa Del Rey in Spanish basketball. One hundred and forty matches were analysed, starting from the 1995-96 to the 2014-15 season. Data were gathered from the official competition web page (www.acb.com). The variables analysed included rule modifications, the number of ball possessions, points scored, one, two and 3-point field goals made and attempted, total rebounds, defensive and offensive rebounds, assists, steals, turnovers, blocked shots, dunks and committed and received personal fouls, score differences, as well as one, two and 3-point field-goal percentages. Several analyses were carried out: descriptive analysis to characterise the sample; ANOVA to identify differences between periods; discriminant analysis to determine technical-tactical performance indicators which best discriminated between each competition term and rule change period; and finally autocorrelation function and cross-correlation were used to estimate the persistency of performance indicators over time. Results show that rule changes affect the way basketball is played. Nevertheless, players and coaches are the ones who determine functional behavior in basketball.
\end{abstract}

Key words teams sports; performance analysis; consistency.

\section{Introduction}

Interpretation of sports rules is a tool widely used by coaches in order to improve performance of their teams and athletes (Gracia et al., 2014; Hill-Haas et al., 2010). Sports rule modifications, such as in court dimensions or the number of active players, may cause an improvement in athletes' physical conditioning (Cormery et al., 2008; Klusemann et al., 2012; Mikołajec et al., 2012), as well as technical (Delextrat and Martinez, 2014) and tactical skill levels (Sampaio and Maçãs, 2012). The effect of rule modification has always been associated with a variation in performance in different team sports (O'Donoghue, 2009). In particular, rule modifications have been associated with technical, tactical and strategic aspects of performance in competition (Pollard, 2008). From the performance analysis perspective, rule modifications allow analysts to recognise the nonlinear and unpredictable nature of team's

\footnotetext{
1 - Faculty of Sports Sciences, University of Extremadura, Caceres, Spain.

2 - Facultad de Educación, Universidad Autonoma de Chile, Santiago de Chile, Chile.

3 - Faculty of Physical Activity and Sport Sciences, Polytechnic University of Madrid, Madrid, Spain.

4 - GOERD Research Group, Universidad de Extremadura, Spain.
} 
performance when facing these changes. The available research was uniform, highlighting the key performance indicators for winning a game that were mainly dependent on the quantity of field goals made and the defensive rebounds (Sampaio et al., 2015). Most of these studies analysed team's performance in a specific season. However, they were not focused on a long-term period considering the persistence and consistency of the sport performance profiles (Shafizadeh et al., 2013).

Rule modifications in basketball have been useful to modify dynamics of the game over time (Pluta et al., 2014). These rule modifications, such as those implemented in training through small-sided games, cause adaptations on the part of the athletes and the appearance of new behaviours emerging from the new limitations (Silva et al., 2014). Specifically, rule modifications are necessary for the development of the sport. In particular, new rules allow matching the game to the current players' demands, both physically and technically. For instance, the increase in the distance of the three-point line was implemented in order to stimulate development in players' skills and technique (Pluta et al., 2014). Another modification was that due to the improvement in some athletes' abilities and physical fitness, spaces were created within the paint called nocharge semicircles to avoid violent contact near the basket. Players are continually evolving physically, and athleticism is a characteristic of current defensive and offensive players (e.g., rough contact, aggressive defences and attacks close to the basket). If defensive players tried to occupy a space near the rim in the attacker's trajectory in order to achieve an offensive foul, the contact would be violent and cause an injury. All of these modifications have caused changes in coaches' strategies and tactics, as they design their training sessions according to the new regulations and the possible scenarios which might occur during games (García-Rubio et al., 2015).

In basketball, according to the International Basketball Federation (FIBA), rules are periodically and constantly evolving over time. The last important modification of the FIBA basketball rules took place during the 2010/11 season. Among others, the main modifications affected formal aspects of the game, such as the distance of the three-point line, and structural aspects, such as restarting the 24-s shot clock. Previously, during the 2000 season, changes were introduced which concerned the temporal aspects of the game, modifying the time for ball possession from 30 to $24 \mathrm{~s}$, establishing four periods (i.e., quarters) instead of two (i.e., halves) and also changing the duration of these periods from 20 to 10 min each (Cormery et al., 2008). In basketball, rule modifications are oriented towards providing a more attractive game, in which teams could get more ball possession per game, attempt more shots, score more points and, by extension, put on a bigger show. This recent rule modification (2010-2011) in basketball has led to an increase in the number of ball possession and points scored per game, thus achieving the desired effect (Štrumbelj et al., 2013). In this regard, one of the elements that allows studying and recording possible changes in performance patterns are the team's performance indicators (field-goal shots, rebounds, assists, etc.) from a long-term perspective.

To the best of our knowledge, there are no studies which analyse the evolution of basketball depending on the changes in the rules of the game and their relevance for performance indicators, minimising the effect of situational variables. Likewise, in some sports like basketball, there are some competitions in which the effect of playing as the local team is reduced to its minimal expression. An example of the great international relevance of this type of competition in FIBA basketball is the Copa Del Rey in the Spanish league. In this competition, only the best-qualified teams at the end of the first round of the ACB league regular season (teams with a similar competitive level according to Pluta et al., 2014) participate, and they play on neutral courts in just one eliminatory game.

Taking the aforementioned issues into account, the objectives of this study were i) to characterise and identify the technical-tactical performance indicators which discriminated the effect of rule modifications, and ii) to analyse the persistence of these indicators according to rule modifications over time. This study had two hypotheses. The first was that technical-tactical performance indicators have evolved according to the rule modifications and the second ii) that performance indicators may show persistence over the different seasons. 


\section{Methods}

\section{Sample}

All data were gathered from the official competition web page (www.acb.com). Analyses were made of all the editions of the current competitive system of the Copa Del Rey in Spanish basketball. A total of 140 matches were analysed, starting from the 1995-96 season to the 2014-15 season. Differences according to the type of competition have been found in basketball regarding performance indicators which discriminate between winners and losers (García et al., 2013) or the advantages of playing at home, both in the strategies used (Gomez et al., 2010), and in performance indicators (García et al., 2014). In the Copa Del Rey, all the teams played on the same court and in just one qualifying match where the best eight teams of the first stage of the regular season participated in the competition. This competition minimises the effects of situational variables when comparing several seasons as it always maintains the same format and competitive level. The local Institutional Review Board approved this study.

\section{Variables}

The independent variable in the study was the change of rules. This variable refers to the period of time in which competition took place using the same FIBA basketball regulations. Three periods with different regulations were analysed. The first period, 1995-2000 (R1995), was established as the base line into which changes were introduced (FIBA, 1994). The second period, 2001-2010 (R2001), was when rule changes that took place were mainly related to structural elements of the sport regarding temporal factors (FIBA, 2000). Ball possession time was reduced from 30" to 24" (Rule 6, art. 39), the time to advance the ball over the midcourt was reduced from $10^{\prime \prime}$ to $8^{\prime \prime}$ (Rule 6, art. 38), and the change from 2 to 4 game periods with 2 min rest periods between the $1^{\text {st }}$ and $2^{\text {nd }}$, and between the $3^{\text {rd }}$ and $4^{\text {th }}$ quarters (Rule 5, art. 17). During the third period, from 2011 to 2015 (R2011), rules regarding structural modifications were mainly related to spatial factors (FIBA, 2010). The distance of the three-point shot line was increased (Rule 2, art. 2.4.4); the shape of the restricted area was modified (Rule 2, art. 2.4.3); the restricted area arc was created inside the zone (Rule 2, art. 4.4.7); and a modification was added to the place from which a player inbounds the ball after a time-out in the last $2 \mathrm{~min}$ of the game (Rule 4, art. 17). On a temporal level, new indications were included on how and when to start the $24 \mathrm{~s}$ ball possession (Rule 5, art. 29).

Primary dependent variables in all of the conducted analyses were technical-tactical performance indicators, recorded by the organisation of the championship: points scored, number of ball possessions, two and 3-point field goals made and attempted, free throws made and attempted, total rebounds, defensive and offensive rebounds, assists, steals, turnovers, blocked shots, dunks and committed and received personal fouls. Secondary variables, calculated based on primary variables were score differences, two and 3-point field-goal percentages, free-throw percentage and number of ball possession situations.

Subsequently, performance indicators were normalised to 100 ball possession situations (BP) (Oliver, 2004) according to the equation (BP = attempted field shots - offensive rebounds + turnovers $-0.4 \mathrm{x}$ attempted free throws). The data normalisation process made it possible to eliminate the "game pace" effect (Ibáñez et al., 2003).

\section{Procedure}

The data were recorded by the official technicians of the competition for each team. The technicians had been trained to collect data live through systematic observation and worked in pairs, and while one made the observations, the other introduced the data in the specific software. Data reliability provided by this competition had been already tested in previous studies (García et al., 2014; Gómez et al., 2015). Additionally, in order to guarantee the validity of the performance indicators, data reliability calculations were conducted via the multirater $\kappa$ free index (Randolph, 2005), analysing a subsample defined by 2 matches from each of the rule change periods (6 matches). The obtained data were contrasted with the official information on the competition by two highly qualified judges. Kappa index values higher than .95 were obtained from all the variables, except for assists, which obtained a value of .89. According to Landis and Koch (1977), the reliability could be classified as nearly perfect. Data analysis

First, to check the distribution of the data, 
the Kolmogorov-Smirnov test was used (Field, 2009). The analysis showed a normal distribution, which allowed the use of parametric tests. An exploratory descriptive analysis was conducted along with the calculation of the means and standard deviation of technical-tactical performance indicators according to the rule changes. These variables were standardised via $\mathrm{z}-$ scores or normal scores, facilitating the subsequent analysis (Ibáñez et al., 2003). An analysis of variance (ANOVA) was conducted in order to identify the differences in the means between each rule-change period. The Bonferroni's post-hoc correction was utilised for two-by-two comparisons (Field, 2009). Also, effect sizes were calculated using Cohen's d, and mean differences as well as confidence intervals were reported. Subsequently, discriminant analysis was used in order to identify technical-tactical performance indicators which best discriminated between each competition term and rule-change period (Ntoumanis, 2003). Centroids indicated the mean variate for each group (Field, 2009). Structural coefficients (SCs) with values higher than $|.30|$ allowed identification of SCs which were the ones that best contributed to the differentiation between the evolution of the regulations (Tabachnick and Fidell, 2001). The higher the SC values, the bigger the contribution of technical-tactical performance indicator to the discriminating function.

Secondly, an autocorrelation function was used to estimate the persistence of each performance indicator over time (Shafizadeh et al., 2013). This function allows establishing the relation in time of a series of events. For this study, a period (lag) with the value of 1 was used to analyse the relationship of each technicaltactical performance indicator in one specific season with regard to the forthcoming seasons. The positive values of the correlation indicated persistence in time of that specific indicator: the higher the value, the stronger the persistence in subsequent seasons. Additionally, crosscorrelation was used for the analysis of game technical-tactical performance indicators which were discriminant as a function of ball possession. In addition the time series analysis (autocorrelation and cross correlation function) included the $r$ value associated to a level of measure: $\geq 0.1, \geq 0.3, \geq 0.5, \geq 0.7$, and $\leq 0.9$ as very poor, marginal, moderate, strong and nearly perfect, accordingly (Hopkins et al., 2009). All analyses were carried out using SPSS 20.0 software (SPSS Inc., Chicago IL, USA). Statistical significance was established as $p<.05$.

\section{Results}

Means and standard deviations for each rule change are presented in Table 1 . The results display, for instance, that the regulation in which more three-point shots were made and attempted was the one where the three-point line was further away (R2011); that the number of ball possession slightly increased throughout the 20 seasons; or that more two-point shots were made and attempted with the initial regulations. ANOVA results along with the Bonferroni posthoc correction are presented in Table 2. The data display significant differences among regulations in almost all technical-tactical performance indicators, except for points scored, offensive rebounds, three-point percentage, and received and performed blocks. The R1996 and R2011 regulations showed the most differences between them, being the most distanced in time, followed by differences between R2001 and R2011.

Discriminant analysis revealed two statistically significant functions. The first function explained $66 \%$ of the variance (Correlation Coefficient $=.64$ ), while the second discriminant function explained $34 \%$ of the variance $($ Correlation Coefficient $=.51)($ Table 1$)$. Structural coefficients of the first discriminant function allowed identification of the two-point shots $(\mathrm{SC}=.35)$, three point field goals made $(\mathrm{SC}=$ $.30)$ and attempted $(\mathrm{SC}=.36)$, one point field goals made $(\mathrm{SC}=.33)$ and attempted $(\mathrm{SC}=.44)$. The second discriminant reflected the importance of two-point field goals made $(\mathrm{SC}=.43)$ and attempted $(\mathrm{SC}=.41)$, ball turnovers $(\mathrm{SC}=.40)$, ball steals $(\mathrm{SC}=.36)$, and received $(\mathrm{SC}=.34)$ and committed $(\mathrm{SC}=.31)$ fouls. The obtained discriminant functions correctly classified $70 \%$ of the cases. Centroids indicated, for function 1, that positive values were associated with the third group of rule periods (R2011), while negative values were related to the base rule period (R1995). The second rule period (R2001) was located in the central area. In the discriminant function 2, periods R1995 and R2011 obtained positive values, while rule period R2001 showed 
negative values. It seems clear that the discriminant function 2, as differences between rule periods R1995 and R2011 have already been explained, established the differences between rule period R2001 and the rest.

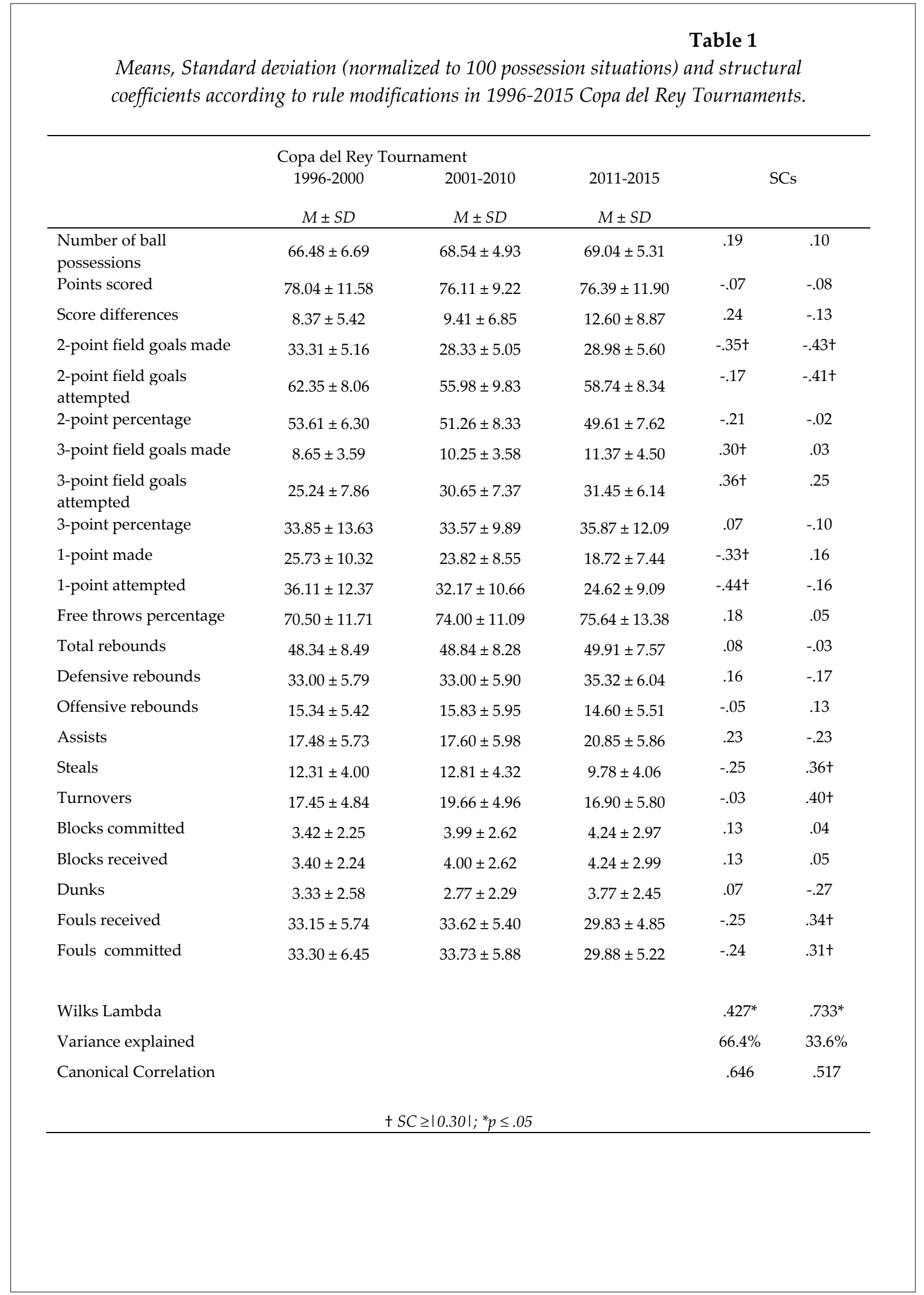


Table 2

Univariate Differences. Mean Differences, 95\% interval confidence and effect size of post-hoc comparison in 1996-2015 Copa del Rey Tournaments.

Copa del Rey Tournament

\begin{tabular}{|c|c|c|c|c|c|c|c|c|c|c|c|c|c|c|c|}
\hline \multirow{4}{*}{$\begin{array}{c}\text { Number of ball } \\
\text { possession }\end{array}$} & \multicolumn{5}{|c|}{$1996-2000$ vs $2001-2010$} & \multicolumn{5}{|c|}{$1996-2000$ vs $2011-2015$} & \multicolumn{5}{|c|}{ 2001-2010 vs 2011-2015 } \\
\hline & & \multirow{2}{*}{$M D$} & \multicolumn{2}{|c|}{$95 \% C I$} & \multirow{2}{*}{ ES } & & \multirow{2}{*}{$M D$} & \multicolumn{2}{|c|}{$95 \% C I$} & \multirow{2}{*}{ ES } & & \multirow{2}{*}{$M D$} & \multicolumn{2}{|c|}{$95 \% C I$} & \multirow{2}{*}{ ES } \\
\hline & & & $L$ & $U$ & & & & $L$ & $U$ & & & & $L$ & $U$ & \\
\hline & $.03^{*}$ & $\begin{array}{c}- \\
2.05\end{array}$ & $\begin{array}{c}- \\
4.00\end{array}$ & -.11 & .35 & $.02^{*}$ & -2.5 & $\begin{array}{c}- \\
4.80\end{array}$ & -.31 & .42 & 1.00 & -.50 & $\begin{array}{c}- \\
2.44\end{array}$ & 1.44 & $\begin{array}{l}.0 \\
9\end{array}$ \\
\hline Points scored & 1.00 & .28 & $\begin{array}{c}- \\
3.44\end{array}$ & 4.00 & .18 & 1.00 & $\begin{array}{c}- \\
1.66\end{array}$ & $\begin{array}{c}- \\
5.96\end{array}$ & 2.64 & .14 & .63 & $\begin{array}{c}- \\
1.94\end{array}$ & $\begin{array}{c}- \\
5.66\end{array}$ & 1.79 & $\begin{array}{l}.0 \\
2\end{array}$ \\
\hline Score differences & $.01^{* *}$ & 3.19 & .68 & 5.69 & .16 & $.00^{* *}$ & 4.23 & 1.33 & 7.12 & .57 & .95 & 1.04 & $\overline{1.46}$ & 3.55 & $\begin{array}{l}.4 \\
0\end{array}$ \\
\hline $\begin{array}{l}\text { 2-point field goals } \\
\text { made }\end{array}$ & .82 & .63 & -.76 & 2.01 & .97 & $.01^{* *}$ & $\begin{array}{c}- \\
2.10\end{array}$ & $\begin{array}{c}- \\
3.70\end{array}$ & -.50 & .80 & $.00^{* *}$ & $\begin{array}{c}- \\
2.73\end{array}$ & $\begin{array}{c}- \\
4.11\end{array}$ & $\begin{array}{c}- \\
1.34\end{array}$ & $\begin{array}{l}.1 \\
2\end{array}$ \\
\hline $\begin{array}{l}\text { 2-point field goals } \\
\text { attempted }\end{array}$ & .07 & 2.22 & -.12 & 4.57 & .70 & 1.00 & -.87 & $\begin{array}{c}- \\
3.58\end{array}$ & 1.84 & .44 & $.01^{* *}$ & $\begin{array}{c}- \\
3.09\end{array}$ & $\begin{array}{c}- \\
5.44\end{array}$ & -.75 & $\begin{array}{l}.3 \\
0\end{array}$ \\
\hline 2-point percentage & .43 & $\begin{array}{c}- \\
1.65\end{array}$ & $\begin{array}{c}- \\
4.36\end{array}$ & 1.06 & .31 & $.01^{* *}$ & $\begin{array}{c}- \\
4.00\end{array}$ & $\begin{array}{c}- \\
7.13\end{array}$ & -.87 & .57 & .11 & $\begin{array}{c}- \\
2.35\end{array}$ & $\begin{array}{c}- \\
5.06\end{array}$ & .36 & $\begin{array}{l}.2 \\
1\end{array}$ \\
\hline $\begin{array}{l}\text { 3-point field goals } \\
\text { made }\end{array}$ & .12 & .81 & -.13 & 1.74 & .45 & $.00^{* *}$ & 2.03 & .95 & 3.11 & .66 & $.01^{* *}$ & 1.22 & .29 & 2.16 & $\begin{array}{l}.2 \\
7\end{array}$ \\
\hline $\begin{array}{l}\text { 3-point field goals } \\
\text { attempted }\end{array}$ & 1.00 & .69 & $\begin{array}{c}- \\
1.11\end{array}$ & 2.49 & .71 & $.00^{* *}$ & 4.94 & 2.87 & 7.02 & .88 & $.00^{* *}$ & 4.25 & 2.45 & 6.05 & $\begin{array}{l}.1 \\
1\end{array}$ \\
\hline 3-point percentage & .52 & 2.30 & $\begin{array}{c}- \\
1.75\end{array}$ & 6.35 & .02 & .90 & 2.01 & $\begin{array}{c}- \\
2.66\end{array}$ & 6.69 & .15 & 1.00 & -.29 & $\begin{array}{c}- \\
4.34\end{array}$ & 3.76 & $\begin{array}{l}.2 \\
1\end{array}$ \\
\hline $\begin{array}{l}\text { 1-point field goals } \\
\text { made }\end{array}$ & $.00^{* *}$ & $\begin{array}{c}- \\
3.42\end{array}$ & $\begin{array}{c}- \\
5.54\end{array}$ & $\begin{array}{c}- \\
1.30\end{array}$ & .20 & $.00^{* *}$ & $\begin{array}{c}- \\
4.10\end{array}$ & $\begin{array}{c}- \\
6.55\end{array}$ & $\begin{array}{c}- \\
1.65\end{array}$ & .77 & 1.00 & -.68 & $\begin{array}{c}- \\
2.80\end{array}$ & 1.44 & $\begin{array}{l}.6 \\
3\end{array}$ \\
\hline $\begin{array}{l}\text { 1-point field goals } \\
\text { attempted }\end{array}$ & $.00^{* *}$ & $\begin{array}{c}- \\
5.05\end{array}$ & $\begin{array}{c}- \\
7.62\end{array}$ & 2.48 & .34 & $.00^{* *}$ & $\begin{array}{c}- \\
6.81\end{array}$ & $\begin{array}{c}- \\
9.78\end{array}$ & $\begin{array}{c}- \\
3.85\end{array}$ & 1.05 & .30 & $\begin{array}{c}- \\
1.76\end{array}$ & $\begin{array}{l}- \\
4.33\end{array}$ & .80 & $\begin{array}{l}.7 \\
6\end{array}$ \\
\hline $\begin{array}{l}\text { Free throws } \\
\text { percentage }\end{array}$ & 1.00 & 1.64 & $\begin{array}{c}- \\
2.54\end{array}$ & 5.82 & .30 & $.03^{*}$ & 5.14 & .31 & 9.97 & .41 & .13 & 3.50 & -.68 & 7.68 & $\begin{array}{l}.1 \\
3\end{array}$ \\
\hline Total rebounds & .77 & .96 & $\begin{array}{c}- \\
1.07\end{array}$ & 2.98 & .05 & $.04^{*}$ & 2.43 & .09 & 4.77 & .19 & .24 & 1.47 & -.55 & 3.50 & $\begin{array}{l}.1 \\
3\end{array}$ \\
\hline $\begin{array}{l}\text { Defensive } \\
\text { rebounds }\end{array}$ & $.02^{*}$ & 1.72 & .20 & 3.24 & .00 & $.00^{* *}$ & 2.47 & .72 & 4.23 & .39 & .71 & .75 & -.77 & 2.27 & $\begin{array}{l}.3 \\
8\end{array}$ \\
\hline $\begin{array}{l}\text { Offensive } \\
\text { rebounds }\end{array}$ & .52 & -.76 & $\begin{array}{c}- \\
2.11\end{array}$ & .58 & .08 & 1.00 & -.04 & $\begin{array}{c}- \\
1.60\end{array}$ & 1.51 & .13 & .59 & .72 & -.62 & 2.07 & $\begin{array}{l}.2 \\
1\end{array}$ \\
\hline Assists & $.00^{* *}$ & 2.32 & .90 & 3.74 & .02 & $.00^{* *}$ & 2.83 & 1.19 & 4.47 & .58 & 1.00 & .51 & -.91 & 1.93 & $\begin{array}{l}.5 \\
4\end{array}$ \\
\hline Steals & $.00^{* *}$ & $\begin{array}{c}- \\
1.99\end{array}$ & $\begin{array}{c}- \\
3.03\end{array}$ & -.94 & .12 & $.02^{*}$ & $\begin{array}{c}- \\
1.40\end{array}$ & $\begin{array}{c}- \\
2.61\end{array}$ & -.19 & .62 & .54 & .59 & -.46 & 1.63 & $\begin{array}{l}.7 \\
2\end{array}$ \\
\hline Turnovers & $.00^{* *}$ & $\begin{array}{c}- \\
1.81\end{array}$ & $\begin{array}{c}- \\
3.11\end{array}$ & -.50 & .45 & 1.00 & .09 & $\begin{array}{c}- \\
1.42\end{array}$ & 1.59 & .10 & .00 & 1.89 & .59 & 3.20 & $\begin{array}{l}.5 \\
1\end{array}$ \\
\hline Blocks committed & 1.00 & .21 & -.43 & .85 & .32 & .10 & .66 & -.08 & 1.40 & .31 & .29 & .44 & -.20 & 1.08 & $\begin{array}{l}.0 \\
8\end{array}$ \\
\hline Blocks received & 1.00 & .21 & -.43 & .85 & .24 & .09 & .67 & -.07 & 1.41 & .31 & .26 & .46 & -.18 & 1.10 & $\begin{array}{l}.0 \\
8\end{array}$ \\
\hline Dunks & $.01^{* *}$ & .69 & .12 & 1.27 & .23 & .54 & .37 & -.29 & 1.04 & .17 & .54 & -.32 & -.90 & .25 & $\begin{array}{l}.4 \\
2\end{array}$ \\
\hline Fouls received & $.00^{* *}$ & $\begin{array}{c}- \\
2.44\end{array}$ & $\begin{array}{c}- \\
3.80\end{array}$ & $\begin{array}{c}- \\
1.07\end{array}$ & .08 & .12 & $\begin{array}{c}- \\
1.36\end{array}$ & $\begin{array}{c}- \\
2.93\end{array}$ & .22 & .62 & .17 & 1.08 & -.29 & 2.44 & $\begin{array}{l}.7 \\
3\end{array}$ \\
\hline Fouls committed & $.00^{* *}$ & $\begin{array}{c}- \\
2.46\end{array}$ & $\begin{array}{c}- \\
3.82\end{array}$ & $\begin{array}{c}- \\
1.10\end{array}$ & .02 & .10 & $\begin{array}{c}- \\
1.39 \\
\end{array}$ & $\begin{array}{c}- \\
2.96\end{array}$ & .19 & .63 & .18 & 1.07 & -.29 & 2.43 & $\begin{array}{l}.6 \\
7\end{array}$ \\
\hline
\end{tabular}

${ }^{*} p \leq .05 ;{ }^{* *} p \leq . .01 ; M D$ : Mean Difference; CI: Confidence Interval; U: Upper L: Lower; 


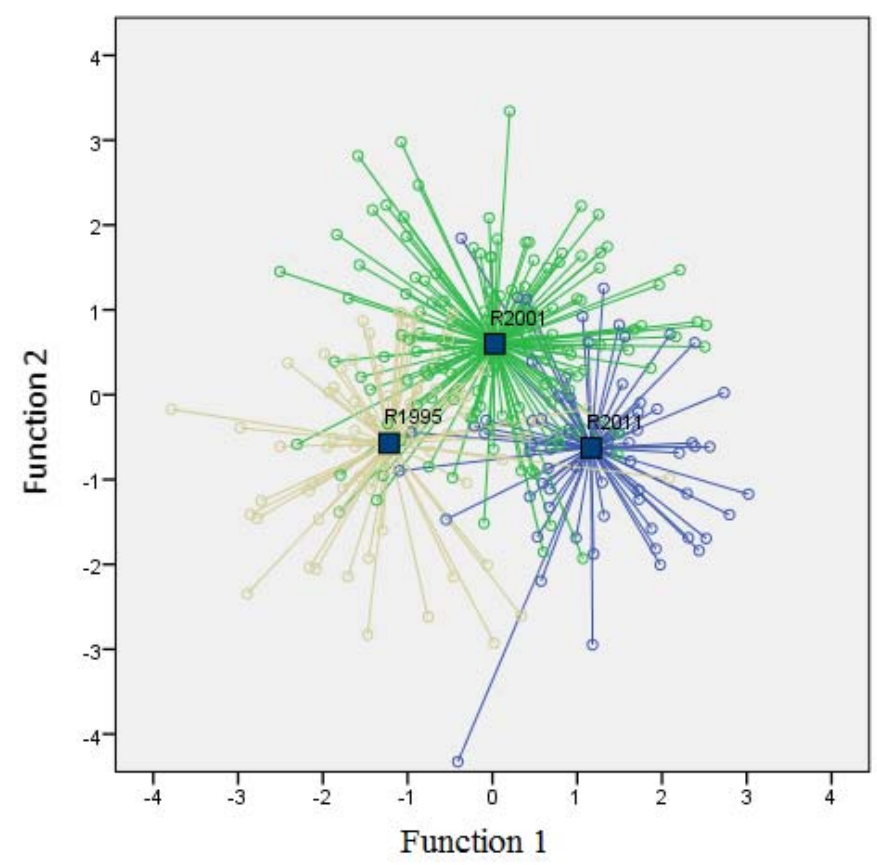

Figure 1

Territorial map from the created clusters according to rule modifications.

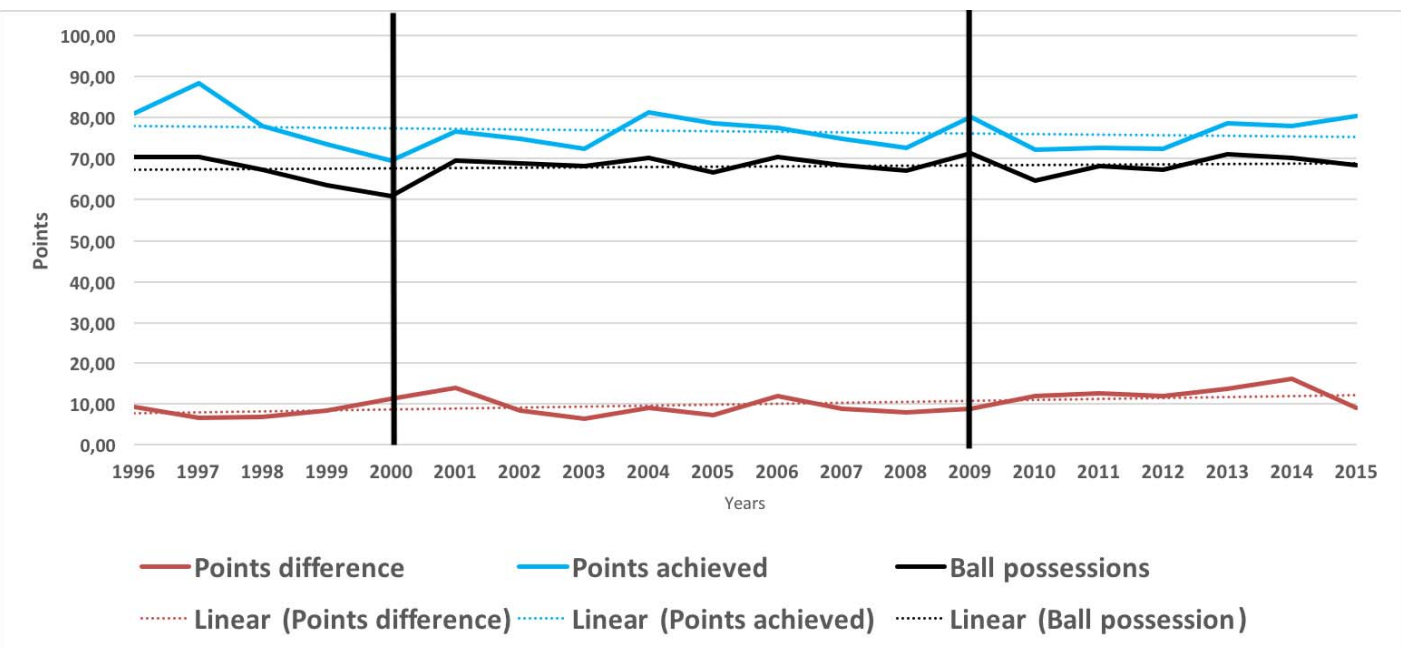

Figure 2

Evolution of the number of ball possession, scored points and point difference according to the season. The vertical lines indicate rule modification. 
Table 3

Autocorrelation (ACF) and cross-correlation (CCF) values for the studied variables. $A C F$ values indicated the relation with itself in following seasons.

CCF values indicated the relation of each variable with the number of ball possession across seasons.

\begin{tabular}{lccc}
\hline Variables & ACF & Sig. & CCF \\
\hline Number of ball possession & 0.45 & $.00^{* *}$ & 1.0 \\
Points scored & 0.22 & $.00^{* *}$ & 0.50 \\
2-point field goals made & 0.15 & $.01^{* *}$ & -0.09 \\
2-point field goals attempted & 0.06 & .25 & -0.14 \\
& & & \\
3-point field goals made & 0.15 & $.00^{* *}$ & -0.01 \\
3-point field goals attempted & 0.12 & $.04^{*}$ & 0.02 \\
Free-throws made & 0.03 & .61 & -0.05 \\
Free-throws attempted & 0.11 & .45 & 0.13 \\
& 0.00 & .96 & 0.04 \\
Steals & & & \\
Turnovers & 0.06 & .29 & 0.04 \\
Fouls committed & 0.18 & $.00^{* *}$ & -0.25 \\
Fouls received & 0.06 & .28 & -0.10 \\
& $* p \leq .05 ;{ }^{* *} p \leq .01$ & & \\
\hline
\end{tabular}

Figure 1 depicts the distribution map of all cases according to the groups of rule periods, created in the space of the two functions. It can be observed that games pertaining to rule period R2001 had better scores in function 2, whereas rule periods R1995 and R2011 had better scores in function 1 .

Figure 2 displays the evolution of the number of ball possession, scored points and point differences between the analysed seasons and the associated trend lines. It can be seen how rule modification had an acute effect on the analysed variables, but decreased over time. Additionally, trend lines show that both the number of ball possession and point difference presented a positive tendency, but achieved points decreased over time. This information is completed with that obtained from the analysis of the autocorrelation and the cross-correlation between the discriminant technical-tactical performance indicators according to the modification of ball possession rules (Table 3). In the autocorrelation function, positive autocorrelations were observed in all technical-tactical performance indicators analysed, and they were only significant in ball possession, points scored, two-point field goals made, three-point field goals made and attempted, free throws attempted, and committed fouls. The values do not display stable persistence over time, except for the case of the number of ball possession. Cross-correlation results of ball possession with the rest of the analysed technicaltactical performance indicators display positive correlations for scored points, three-point shots attempted, free throws attempted, steals and turnovers.

\section{Discussion}

The aim of this research was to identify performance indicators that best discriminated among periods of rule changes in basketball and their effects during the period analysed. In this regard, the results display differences in the number of ball possession and an increase of the 
game pace over the last few years, but points scored did not increase during the analysed time periods. Results allow to partially support the hypothesis that rule modifications generate changes in teams' performance measured using game statistics. Regarding the evolution of basketball, this sport has changed during the last 20 seasons of the professional Spanish league (ACB League), where 3 periods of time with substantial rule modifications have taken place, all of them with the objective of making a more dynamic, attractive, spectacular and pleasing sport, which could increase both the number of spectators and its popularity (Pluta et al., 2014).

Statistically significant differences have been found between primary technical-tactical performance indicators over time. Nevertheless, technical-tactical performance indicators which maximise the differences between each rule period are scarce. One of the objectives of rule modification is to increase the game pace and therefore, to speed up offensive play in order to increase viewership. This intended objective was not found in the present study, as the aforementioned performance indicators did not discriminate between the analysed periods. For this reason, a complementary analysis was conducted in order to study the persistence of the technical-tactical performance indicators through the changes produced in the regulations, as well as the association of the indicators with the number of ball possession situations over time.

The first rule modification (R2001) characterised the game with a greater number of steals and turnovers, the lowest number of tried and successful two-point shots, as well as an increment in fouls. Steals are an indicator of defensive pressure normally performed by perimeter players (Sampaio et al., 2006). Likewise, this defensive pressure may force attacking players to engage in unnecessary dribbling or bad passes, thus attaining more steals (Ibáñez et al., 2008) or turnovers. In this regard, it has been demonstrated that the more physically fit players can intensify defensive pressure, increasing the chances of steals and turnovers from the opposing team (Dežman et al., 2001). Nevertheless, steals and turnovers decreased following the last rule modification, whereas players have improved their physical and tactical profiles due to a better formative process during training and the rule modifications generating an adaptation of the athletes to game demands (Cormery et al., 2008). This abrupt reversal in the number of steals and turnovers can be explained by the modifications in referee's criteria (Štrumbelj et al., 2013). In the evolution from regulation period R2001 to R2011, the dimensions of the playing field were modified. In the R2001 period, the three-point line was closer to the basket than in R2011. The effective game space was smaller, making passing more difficult, defensive help was faster thus increasing the number of steals and turnovers compared to R2011. In the next regulation evolution, effective game space was increased as the three-point line moved further away from the basket, which also may explain (referee's criteria) the lower number of turnovers and steals.

In the current period of the game, R2011, the three-point line moved further away from the basket. This change was motivated by the increase in the use of the 3-point field goal (25.24 vs. 30.65) (Štrumbelj et al., 2013). The balance between the inside and outside game in basketball in order to select a shot, along with the existence of more physical outside players, generate more advantages in three-point shooting (Mavridis et al., 2003). However, the separation of the threepoint line has paradoxically induced a slight increment in the use and efficacy (made shots/attempted shots) of this type of a shot. Players have specialised in this type of a shot and are capable to perform successfully in the game (Štrumbelj et al., 2013) as they have developed greater mastery of basketball techniques, skills and decision-making (Pluta et al., 2014). This demonstrates that the game has a greater athletic component in order to generate better passing lines and 1-on-1 actions, which produce mismatches (Erčulj and Štrumbelj, 2015; Skinner, 2012). The increase in the distance of the threepoint shot has not been sufficient to diminish the efficacy percentages; in fact, coaches are aware of the importance of precision in this type of shooting, which along with two-point shots, has been one of the most important predictors of victory in the ACB league for 10 seasons (20032013) (Puente et al., 2015). On the other hand, because of the extra effective game space, pressure defence has diminished at the time of performing a shot, as defensive players have to cover more play areas. Three-point shooting 
defence demands a greater distance to be covered, and thus, higher energy consumption (Erčulj and Štrumbelj, 2015; Ibáñez et al., 2009; Reilly, 1997). As pressure defence decreases, shot efficacy increases (Ibáñez et al., 2009).

A decrease in attempted free throws has been identified throughout the analysed time periods. During the R2001 period, there was a modification of the temporal structure of the game, changing from two 20 min periods to four 10 min periods of play. This modification of the regulations affects the moment at which free throws are performed due to an accumulation of personal fouls, starting from the seventh to the fourth personal foul. The aforementioned rule modification allows teams to increase their pressure defence, commit one extra foul $(4+4)$ without the risk of sending the opponent to the free-throw line. Expert coaches are aware of these circumstances and exploit the opportunities provided by the regulations in order to score points and to break the game pace (Štrumbelj et al., 2013). Also, players have adapted to the new rules, committing less personal fouls than before (Štrumbelj et al., 2013).

The technical-tactical performance indicator which displays the strongest persistence throughout the analysed seasons was the number of ball possession situations. Although the specialised literature shows that the best teams play with a smaller number of possession situations (Ibáñez et al., 2003, 2008), the rules seek to evolve towards a faster game pace. Additionally, coaches seek to reduce the game pace during the most important matches, like qualifications for the finals or a match that would have a direct impact on the future of the team (García et al., 2013; Sampaio and Janeira, 2003). The Copa Del Rey championship has a singleelimination format, in which coaches risk less and have better control of the game pace. In fact, results show that when the game pace increases, the number of turnovers also increases significantly. It has also been demonstrated that when the game pace is higher, inaccuracies keep increasing, thus incrementing the number of steals and fouls committed (Sampaio et al., 2010). Due to this, those teams with better physical and tactical preparation, such as in the NBA, impose a very fast game pace with the aim of obtaining a high score advantage during the first half of the match
(Sampaio et al., 2010). Nevertheless, in European league single-elimination games, where teams might be ruled out of the competition, teams decide on a slower game pace. Additionally, the increment in the number of two- and three-point shots when the pace is increased does not modify the success percentage of the aforementioned shots.

\section{Conclusions and Practical Implications}

Through the analysis of performance in basketball, coaches can obtain valid and reliable information regarding their own teams, their opponents, and, in this case, the competition. In this study, significant differences were found in some of the technical-tactical performance indicators among the different rule changes. Thus, a reflective analysis about the modifications of game conditions that the rule change implies should be mandatory (Pluta et al., 2014) in order to validate it. In this sense, according to the ecological systems theory, sports performance is an adaptive process between players and teams in time and space (Travassos et al., 2013). To modify the structural elements of the game regulations, such as temporal or spatial aspects, without establishing measures which modify the interaction between players and teams with functional elements, space and time (Grehaigne et al., 1997), teams must conduct those adaptations which best serve their objectives. These modifications change the players' behaviours in a different manner, as they are the ones who adapt their behaviours and decisions in function of their own expertise, skills, and opponents (Arias et al., 2011). Regulation evolution modifies the structural rules of basketball; nevertheless, players and coaches are the ones who determine functional behaviour in basketball - in other words, the way in which they use the structural rules in order to connect themselves with the field, the game time, opponents and teammates (Arias et al., 2011). Coaches should use these findings to i) create different training scenarios, ii) manage the functional behaviours of players with the structural rules, and iii) take advantage of being aware of rule modifications and the strategies affected.

Finally, there are some limitations that should be addressed in future research. Static analysis simplifies the information into its 
elementary components using the final gamerelated statistics. Therefore, future research should be controlled for technical, tactical and physical information, such as series of discrete events, physical performances and the interactions affected by the quality of the opposition.

\section{Acknowledgements}

This work was partially subsidized by the Ayuda a los Grupos de Investigación (GR15122) of the Junta de Extremadura (Consejería de Economía e Infraestructuras); with the contribution of the European Union through the FEDER.

\section{References}

Arias JL, Argudo FM, Alonso JI. Review of rule modification in sport. J Sports Sci Med, 2011; 10(1): 1

Cormery B, Marcil M, Bouvard M. Rule change incidence on physiological characteristics of elite basketball players: a 10-year-period investigation. Brit J Sport Med, 2008; 42(1): 25-30

Delextrat A, Martinez A. Small-sided game training improves aerobic capacity and technical skills in basketball players. Int J Sport Med, 2014; 35(05): 385-391

Dežman B, Trninić S, Dizdar D. Expert model of decision-making system for efficient orientation of basketball players to positions and roles in the game-Empirical verification. Coll antr, 2001; 25(1): 141152

Erčulj F, Štrumbelj E. Basketball Shot Types and Shot Success in Different Levels of Competitive Basketball. PLoS ONE, 2015; 10(6): e0128885

FIBA. Official Basketball Rules. FIBA, Toronto, Canada; 1994

FIBA. Official Basketball Rules. FIBA, Munich, Germany; 2000

FIBA. Official Basketball Rules. FIBA, San Juan, Puerto Rico; 2010

Field A. Discovering statistics using SPSS: Sage publications; 2009

García-Rubio J, Góme, MA, Cañadas M, Ibáñez SJ. Offensive Rating-Time coordination dynamics in basketball. Complex systems theory applied to Basketball. Int J Perf Anal Sport, 2015; 15(2): 513-526

García J, Ibáñez SJ, Gómez MA, Sampaio J. Basketball Game-related statistics discriminating ACB league teams according to game location, game outcome and final score differences. Int J Perf Anal Sport, 2014; 14(2): 443-452

García J, Ibáñez SJ, Martinez De Santos R, Leite N, Sampaio J. Identifying basketball performance indicators in regular season and playoff games. J Hum Kinet, 2013; 36(1): 161-168

Gomez MA, Lorenzo A, Ibáñez SJ, Ortega E, Leite N, Sampaio J. An analysis of defensive strategies used by home and away basketball teams. Percep Motor Skill, 2010; 110(1): 159-166

Gómez MA, Lorenzo A, Jiménez S, Navarro RM, Sampaio J. Examining chocking in basketball: effects of game outcome and situational variables during last 5 minutes and overtimes. Percept Motor Skill, 2015; 120(1): 111-124

Gracia F, García J, Cañadas, M, Ibáñez SJ. Heart rate differences in small sided games in formative basketball. E-balonmano. com: Revista de Ciencias del Deporte, 2014; 10(1): 23-30

Grehaigne JF, Bouthier D, David B. Dynamic-system analysis of opponent relationships in collective actions in soccer. J Sport Sci, 1997; 15(2): 137-149

Hill-Haas SV, Coutts AJ, Dawson BT, Rowsell GJ. Time-motion characteristics and physiological responses of small-sided games in elite youth players: the influence of player number and rule changes. $J$ Strength Cond Res, 2010; 24(8): 2149-2156

Hopkins W, Marshall S, Batterham A, Hanin J. Progressive statistics for studies in sports medicine and exercise science. Med Sci Sport Exer, 2009; 41(1): 3. 
Ibáñez S, García J, Feu S, Parejo I, Cañadas M. Shot efficacy in the NBA: A multifactorial analysis. Cultura, Ciencia y Deporte, 2009; 10: 39-48

Ibáñez SJ, García J, Feu S, Lorenzo A, Sampaio J. Effects of consecutive basketball games on the game-related statistics that discriminate winner and losing teams. J Sport Sci Med, 2009; 8(3): 458

Ibáñez SJ, Sáenz-López P, Giménez J, Sampaio J, Janeira MA. Game statistics discriminating the final outcome of Junior World Basketball Championship matches (Portugal'99). J Hum Mov Stud, 2003; 45: 01-19

Ibáñez SJ, Sampaio J, Feu S, Lorenzo A, Gómez MA, Ortega, E. Basketball game-related statistics that discriminate between teams' season-long success. Eur J Sport Sci, 2008; 8(6): 369-372

Klusemann MJ, Pyne DB, Foster C, Drinkwater EJ. Optimising technical skills and physical loading in smallsided basketball games. J Sport Sci, 2012; 30(14): 1463-1471

Landis JR, Koch GG. The Measurement of Observer Agreement for Categorical Data. Biometrics, 1997; 33(1): 159-174

Mavridis G, Laios A, Taxildaris K, Tsiskaris G. Developing offense in basketball after a return pass outside as crucial factor of winning. Inquiries in Sport \& Physical Education, 2003; 2(1): 81-86

Mikolajec K, Waskiewicz Z, Maszczyk A, Bacik B, Kurek P, Zając, A. Effects of stretching and strength exercises on speed and power abilities in male basketball players. Isokinet Exerc Sci. 2012; 20(1): 61-69

Ntoumanis N. A Step-by-Step Guide to SPSS for Sport and Exercise Studies: A Step-by-Step Guide for Students: Routledge; 2003

O'Donoghue P. Research Methods for Sports Performance Analysis: Routledge; 2009

Oliver D. Basketball on paper: rules and tools for performance analysis: Potomac Books, Inc; 2004

Pluta B, Andrzejewski M, Lira J. The effects of rule changes on basketball game results in the men's European basketball championships. Hum Mov, 2014; 15(4): 204-208

Pollard R. Home advantage in football: A current review of an unsolved puzzle. The open Sports Sciences Journal, 2008; 1(1)

Puente C, Coso J D, Salinero JJ, Abián-Vicén J. Basketball performance indicators during the ACB regular season from 2003 to 2013. Int J Perf Anal Sport, 2015; 15(3): 935-948

Randolph JJ. Free-Marginal Multirater Kappa (multirater kfree): An Alternative to Fleiss' Fixed-Marginal Multirater Kappa. Paper presented at the Joensuu Learning and Instruction Symposium 2005, Joensuu, Finland; 2005

Reilly T. Energetics of high-intensity exercise (soccer) with particular reference to fatigue. J Sport Sci, 1997; 15(3): 257-263

Sampaio J, Ibanez SJ, Feu, S. Discriminative power of basketball game-related statistics by level of competition and sex. Percept Motor Skill, 2004; 99(3): 1231-1238

Sampaio J, Janeira M. Statistical analyses of basketball team performance: understanding teams' wins and losses according to a different index of ball possessions. Int J Perf Anal Sport, 2003; 3(1): 40-49

Sampaio J, Janeira M, Ibáñez S, Lorenzo A. Discriminant analysis of game-related statistics between basketball guards, forwards and centres in three professional leagues. Eur J Sport Sci, 2006; 6(3): 173178

Sampaio J, Lago C, Drinkwater, EJ. Explanations for the United States of America's dominance in basketball at the Beijing Olympic Games (2008). J Sport Sci, 2010; 28(2): 147-152

Sampaio J, Maçãs V. Measuring tactical behaviour in football. Int J Sport Med, 2012; 33(5): 395-401

Sampaio J, McGarry T, Calleja-González J, Jiménez Sáiz S, Schelling i del Alcázar X, Balciunas M. Exploring Game Performance in the National Basketball Association Using Player Tracking Data. PLoS ONE, 2015; 10(7): e0132894

Shafizadeh M, Taylor M, Peñas CL. Performance consistency of international soccer teams in Euro 2012: A 
time series analysis. J Hum Kinet, 2013; 38: 213-226

Silva P, Duarte R, Sampaio J, Aguiar P, Davids K, Araujo D, Garganta J. Field dimension and skill level constrain team tactical behaviours in small-sided and conditioned games in football. J Sport Sci, 2014; 32(20): 1888-1896

Skinner B. The problem of shot selection in basketball. PLoS ONE, 2012; 7(1): e30776

Štrumbelj E, Vračar P, Robnik-Šikonja M, Dežman B, Erčulj F. A Decade of Euroleague Basketball: an Analysis of Trends and Recent Rule Change Effects. J Hum Kinet, 2013; 38: 183-189

Tabachnick BG, Fidell LS. Using multivariate statistics; 2001

Travassos B, Davids K, Araújo D, Esteves PT. Performance analysis in team sports: Advances from an Ecological Dynamics approach. Int J Perf Anal Sport, 2013; 13(1): 83-95

\section{Corresponding author:}

\section{Javier Garcia-Rubio}

Facultad Educación, Universidad Autónoma de Chile, Ricardo Morales 3369, San Miguel, Región Metropolitana, Chile

E-mail: javier.garcía@uautonoma.cl 